\title{
Aspectos de la gramática del gerundio de posterioridad del castellano
}

Aspects of the grammar of the gerund of posteriority of Spanish

\author{
Víctor Arturo Martel Paredes \\ Universidad Nacional Mayor de San Marcos, Lima, Perú \\ Contacto:vmartelp@unmsm.edu.pe \\ https://orcid.org/0000-0001-5408-6215
}

\begin{abstract}
Resumen
El propósito de este artículo es describir la gramática que subyace a la construcción del llamado gerundio de posterioridad. Se mostrará que, en oposición a París (2003), las construcciones con gerundios no perifrásticos de adjunto ilativos (o de posterioridad) requieren una vinculación entre el evento del verbo finito y el que expresa el gerundio a partir de los individuos (sujeto, objetos e incluso proposiciones) y sus estados (restricciones de aspecto). Nos proponemos describir las restricciones semánticas y aspectuales que permiten interpretar la construcción de gerundio de posterioridad. A su vez, este artículo es una respuesta a la censura a la que es sometido el gerundio de posterioridad en aras del uso de formas prestigiosas y tradicionales, las que, a través de los siglos, los gramáticos han tratado infructuosamente de imponer en el habla y escritura al basarse sobre nociones de gramaticalidad que, a todas luces, no representan la gramática de los hablantes.
\end{abstract}

Palabras clave: Gerundio de posterioridad; Gramática; Semántica

\begin{abstract}
My purpose is to describe the grammar that underlies the construction of the so-called gerund of posteriority. I will show that, in opposition to Paris (2003), constructions with non-periphrastic gerunds with a sense of inference sense of consecution (or posterioriry) require a semantic link between the event of the finite verb and the one that the gerund expresses from individuals (such as subject, objects, including propositions) and their states (restrictions of aspect). My proposal is to describe the semantic and aspectual restrictions that allow to interpret the building construction of the gerund of posteriority. In turn, this article is a response to the censorship to which the gerund of posteriority is subject in the sake of using the use of prestigious and traditional forms, which, through the centuries, grammarians have unsuccessfully tried to impose on speech and writing, based on grammaticality notions of grammaticality that do not represent the grammar of speakers.
\end{abstract}

Keywords: Gerund of posteriority; Grammar; Semantics

Recibido: 23.03 .20

Aceptado: 02.06.20 


\section{Introducción}

El presente artículo tiene como propósito describir la gramática del gerundio de posterioridad, como respuesta a la idea de que se trata de una incorrección y que debería evitarse. Sostendremos esta propuesta sobre el análisis de las respuestas a una encuesta aplicada a hablantes de castellano (véase anexo al final del artículo). La idea que se busca afirmar es que el gerundio de posterioridad se basa sobre restricciones de (a) identificación del individuo participante del evento del verbo finito con el sujeto del gerundio; y (b) condiciones temporales y aspectuales impuestas por (b1) ocurrencia del gerundio inmediatamente después del verbo finito y sus complementos; (b2) ocurrencia de frases adverbiales con denotación de tiempo posterior; (b3) indicación a partir del aspecto gramatical del verbo finito que el evento descrito por este ha concluido; y (b3) el aspecto léxico descrito por el verbo finito.

Para cumplir con dicho objetivo, en el apartado 2, se mencionarán algunos trabajos de gramática sobre el gerundio de posterioridad, como Bello (1847), Cuervo (1954), Gili y Gaya (1964) y Bobes Naves (1975), los cuales califican dicha construcción como una "incorrección", y proponen evitar su uso. Más adelante brindaré aportes menos prescriptivos y más descriptivos del fenómeno (Bouzet, 1953; Fernández, 1999) para introducir la propuesta de París (2003) sobre cómo interactúan los gerundios no perifrásticos con los verbos finitos en la gramática. Ello nos proporcionará una base para nuestra propuesta. En el apartado 3, presentaremos los objetivos del estudio; y, en el apartado 4, expondremos la metodología seguida para recoger los juicios gramaticales de hablantes de castellano. En el apartado 5, se mostrarán los porcentajes obtenidos sobre grados de aceptabilidad de cada oración con gerundios de posterioridad, indicando el porcentaje mayor y el más bajo. Se apreciará que se busca medir el grado de aceptabilidad en oraciones que transgreden el tiempo, aspecto, ubicación del gerundio, entre otros puntos, con el fin de deducir una posible gramática del gerundio de posterioridad. Finalmente, en el apartado 6, contrastaremos los resultados de la aplicación de la encuesta con la propuesta de análisis de París (2003) y brindaremos las conclusiones del estudio en el apartado 7. 


\section{El gerundio de posterioridad: de las gramáticas prescriptivas a su descripción}

La gramática normativa señala que un gerundio denota un evento anterior o simultáneo, pero nunca posterior al referido por el verbo principal. Estudiosos de la lengua española coinciden con tal afirmación, desde un mayor a un menor grado de rechazo a este uso. Andrés Bello se refería a él como "una de las degradaciones que deslucen el castellano moderno" (1972 [1847], p. 446). J. Rufino Cuervo (1954) apunta que "el gerundio denota simple coincidencia de tiempo, o tiempo inmediatamente anterior, nunca posterior" (p. 326); Samuel Gili y Gaya (1964) es más enfático: "la acción verbal que el gerundio indica no puede ser posterior a la del verbo principal. [...] El gerundio no es adecuado para significar posterioridad, consecuencia, o efecto [...] Hay que decir, sin embargo, que tan censurables construcciones van siendo frecuentes" (p. 192). Bobes Naves (1975) explica que "no puede, lógicamente, indicar una acción posterior, puesto que no puede modificar a una acción pasada" (p. 33). Los autores que mencionan los usos correctos y censuran los incorrectos aumentan con los años, pero muy pocos identifican la agramaticalidad del uso, si este acaso es agramatical.

Sobre el gerundio ilativo de posterioridad, se dice que es una incorrección cuando "introduce una mera sucesión temporal" (RAE, 2011, $\$ 27.4 \mathrm{~g})$. Sin embargo, se señala más adelante que "resulta más aceptable cuando la posterioridad denotada es tan inmediata que se percibe casi como simultaneidad y también cuando cabe pensar en una relación inferencial de tipo causal, concesivo o consecutivo" (RAE, 2011, §27.4i). Se cita el siguiente ejemplo: "Confesó públicamente que fue él quien seis años atrás puso las bombas de Fuentes Fluviales, haciendo quedar en ridículo a la batería de abogados liberales que lo defendió en las cortes". La RAE explica que este uso ilativo se debe al carácter "flexible" y adaptable del gerundio que se une al verbo que modifica sin necesidad de nexos subordinantes. Entonces la "agramaticalidad" de estas formas reside en que los gerundios de posterioridad no afectan, como deberían hacer en su calidad de adverbios, a los eventos expresados por la oración principal, ya que no se produce una vinculación sintáctica, es decir, están sintácticamente aislados, por tratarse de proposiciones temporales concatenadas. 
El uso del gerundio con sentido de posterioridad ya data de tiempo atrás, como lo hace ver Bouzet (1953), quien cita ejemplos de textos de los siglos XV y XVIII. El autor, lejos de apostar por la pertinencia del uso debido a su antigüedad, ofrece una explicación lógica, al mencionar que el gerundio de posterioridad no brinda otra cosa que unidad a la idea total enunciada:

El gerundio, liberado de su subordinación temporal y aislado de los verbos aledaños, conserva una característica asociativa innegable, que le permite formar un cuerpo con la frase [...] En rigor, podemos considerar la expresión cerrando la puerta ["Entornó las ventanas para dejar el cuarto a media luz y se salió de puntillas, cerrando la puerta sin hacer el menor ruido"] como aproximación equivalente de y cerró la puerta; sin embargo, el efecto obtenido es diferente: cerró, enuncia un hecho aislado, no es retenido en el contenido de la frase que, por así decirlo, lo hace con la conjunción $y$; pero cerrando, que enuncia un hecho asociado, se encuentra relacionado, se presenta como conclusión de la frase, de la cual la unidad parece así mejor garantizada. (Bouzet, 1953, p. 372; énfasis añadido.)

De los Mozos (1974) rechaza la hipótesis de Badía Margarit (1964) sobre la influencia árabe en la construcción del gerundio de posterioridad e incide en la explicación de que tal construcción es un sentido posible en el sistema verbal español, puesto que la relación temporal depende del contexto y la relación semántica entre los lexemas.

Aproximándonos a la descripción del fenómeno que nos interesa, Fernández Lagunilla (1999, p. 3478) explica que este tipo de construcciones con gerundios se asemeja más a oraciones coordinadas finitas que a las subordinadas adverbiales. Ello se debe a que los ilativos no funcionan como modificadores de la oración principal, sino como oraciones que expresan un evento independiente que acompaña, se suma o añade al denotado en la principal. Además, hace una distinción entre ilativos explicativos que hacen uso de elementos anafóricos ( $p$. e., "Entregó sus papeles, dando con ello una gran alegría") y los de posterioridad (p. e., "El delincuente huyó siendo capturado a la brevedad").

Los gerundios de posterioridad que trataremos en este artículo se encuentran dentro de los denominados adjuntos externos, que son considerados oraciones (construcciones absolutas), pues cuentan con sujeto propio, explícito o tácito, el que puede ser distinto o el mismo de la oración principal, o también el 
sustantivo complemento (OD u OI) de la oración principal. Estos pueden tener las siguientes denotaciones:

Temporales: Entrando María, salía Juan.

Causales: $\quad$ Esperando ganar mucho dinero, los empresarios derribaron las chabolas.

Condicionales: Conociendo a Juan, sabrías que no vendría.

Concesivos: $\quad$ Aun lloviendo a mares, iremos.

Ilativos: Metió la carta en el sobre, cerrándolo a continuación.

Por otro lado, seguimos la propuesta de París (2003) sobre la composición eventiva de las construcciones de gerundio. El autor hace una distinción entre gerundios de complemento y de adjunto. Los de complemento son construcciones de control, en donde el Sujeto silente PRO [pronombre vacío fonéticamente] (Chomsky, 1986) está ligado por un antecedente, en este caso, el Sujeto de la oración principal, como se muestra en (1); mientras que los de adjunto pueden tener sujeto independiente, como se observa en (2), o correferencial con un participante del verbo finito:

(1) Diego caminó $\mathrm{PRO}_{\mathrm{i}}$ silbando la canción que le gustaba.

(2) $\mathrm{PRO}_{\mathrm{ARB}}$ Limpiando las lunas del auto, se puede ver qué hay dentro.

El autor, además, propone que la estructura de gerundio de complementación se explica a partir de una relación interna entre eventos; para ello, al menos una subparte del tiempo de los eventos expresados en la estructura se solapan. Por ejemplo, en la siguiente oración, el evento de 'cantar' comparte al menos una subparte del tiempo $t$ en su desarrollo con una subparte del tiempo $t$ ' del evento 'acordarse'.

"María canta acordándose de la letra".

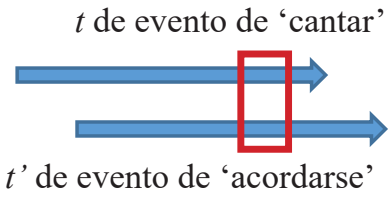

Figura 1. Gerundio no perifrástico de complemento 
Por otro lado, los gerundios de adjunto se interpretan a través de una relación de consecuencia (o causa), en la que no se comprometen sus estructuras internas. En la siguiente oración, el evento 'estudiar' no comparte tiempo de subeventos que se solapen con los de 'salir', pero se puede interpretar una relación de causa o condición entre ellos:

"Estudiando arduamente, Alberto obtendrá la beca".

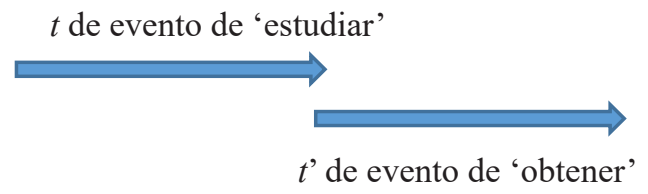

Figura 2. Gerundio no perifrástico de adjunto

Una relación de consecuencia toma dos eventos independientes de cualquier tipo e impone relaciones temporales sobre ellos: el evento causante tiene que preceder temporalmente al efecto y la precedencia necesita ser inmediata (París, 2003, p. 163). Sin embargo, como explica el autor, esta relación de consecuencia no se encuentra codificada ni gramaticalizada en la construcción, sino que es producto de interpretación del contexto lingüístico. Por ejemplo, el orden en el que se presentan los eventos determina la relación de consecuencia entre estos. Así, la interpretación del orden de eventos de la oración

(3) a. "Algunos representantes se escindieron del bloque, abandonando a sus camaradas"

b. "Abandonando a sus camaradas, algunos de los representantes se escindieron del bloque"

donde en (3a) "escindir" es causa de "abandonar", es distinta a la de la oración; y en ( $3 b$ ) el evento de "abandonar" es el causante del evento "escindir". También al introducir un adverbio temporal o frase adverbial como "luego" o "después de un rato" se refuerza la idea de que la relación temporal no está gramaticalizada, sino que es interpretable del contexto.

En resumen, las construcciones de gerundio pueden clasificarse en dos tipos: de complemento y de adjunto. Los gerundios de adjunto son cláusulas semiindependientes que pueden tener un sujeto distinto o el mismo del verbo 
finito. La relación semántica (temporal) que establecen el verbo finito y el gerundio de adjunto no está codificada, sino que es interpretada a través del contexto lingüístico.

Una vez que conocemos la forma en que los gerundios no perifrásticos se estructuran con los verbos finitos en cuanto a su relación temporal, nos planteamos en este artículo proponer una serie de restricciones que permitan describir y explicar la gramática de los gerundios de posterioridad. Para ello, los objetivos del presente trabajo pasan por proponer que el gerundio adjunto de posterioridad, si bien no comparte subpartes temporales de su desarrollo interno con el verbo finito, como aduce París (2003), sí comparte individuos participantes y limitaciones aspectuales impuestas por el verbo finito.

\section{Objetivos}

Los objetivos de este estudio pueden sistematizarse en uno general y tres específicos:

\subsection{General}

Proponer condiciones de formación de gerundios de posterioridad en el castellano a partir de juicios de hablantes de castellano peruano limeño.

\subsection{Especificos}

- Describir la distribución sintáctica de los gerundios de posterioridad con respecto a la oración y a constituyentes adverbiales de tiempo.

- Describir la relación semántica entre los sujetos de los eventos del verbo finito y del gerundio de posterioridad.

- Describir la información aspectual del verbo finito y su relación con el gerundio de posterioridad.

\section{Metodología}

Para llevar a cabo los objetivos del presente estudio, se ha elaborado una encuesta sobre juicios de aceptabilidad sobre construcciones de gerundio de posterioridad que fue aplicada a una muestra aleatoria de 30 hablantes de castellano limeño; es decir, no hubo una selección por estrato socioeconómico, sexo, educación u 
ocupación; aunque se prefirió hablantes mayores de quince años que tuvieran una cuenta de correo electrónico a donde enviar la encuesta. Esta preferencia se debe a que hay una mayor confiabilidad de que los hablantes contesten las preguntas considerando reflexivamente su juicio gramatical. En este cuestionario se observarán los juicios sobre los siguientes puntos:

a. Interpretación del sujeto del gerundio de posterioridad a partir de los participantes del verbo finito.

b. Interpretación de la posterioridad a partir del tiempo verbal del verbo finito.

c. Interpretación del gerundio a partir de su posición con respecto al verbo finito.

d. Interpretación del gerundio sin frases adverbiales de tiempo.

e. Interpretación del gerundio con respecto al aspecto léxico del verbo finito.

\section{Resultados de la aplicación de encuesta}

5.1 Interpretación del sujeto del gerundio de posterioridad a partir de los participantes del verbo finito

De acuerdo con la aplicación de la encuesta, los gerundios de posterioridad pueden compartir el sujeto de la oración principal, como en (4a) (66,7\% interpretó "Los alumnos" como el sujeto; y 33\%, "alguien no especificado").

(4) a. Los alumnos desarrollaron el examen, saliendo dos horas después.

b. Los alumnos desarrollaron el examen, saliendo el profesor dos horas después.

c. Los alumnos desarrollaron el examen, saliendo un profesor dos horas después.

La Frase Determinante (FD) "Los alumnos" es el mismo sujeto tanto para "desarrollaron" como para "saliendo". Por otro lado, el hecho de tener sujetos distintos, como en (4b), degrada la aceptabilidad, ya que el 50\% valoró la oración como "inaceptable"; 33,3\%, como "aceptable"; y el 16,7\% como "extraña pero aceptable". En este caso, quisimos saber si, debido a que el sujeto es una FD 
definida, "el profesor", los hablantes supusieran que formaba parte de la situación descrita por el verbo finito y fuese aceptable. En esa misma línea, se percibió como "inaceptable" la oración donde se introduce la FD indefinida "un profesor", como en (4c): un 50\% la valoró como "inaceptable" y 50\%, como "extraña pero aceptable".

Ahora bien, el sujeto del gerundio puede identificarse con el Objeto Directo (OD) del verbo finito, como en (5a), ya que el 66,7\% identificó el OD con el sujeto del gerundio; y de igual manera, en (5b), un 67,7\% hizo la misma identificación. No obstante, cuando se preguntó sobre la relación entre Objeto Indirecto (OI) y el sujeto del gerundio, se obtuvo en (5c) una identificación OISujeto de gerundio de $33,3 \%$ frente a un $66,7 \%$ con un "Sujeto no especificado" (o extraoracional); y de la misma forma en (5d), un 33\% identificó el OI con Sujeto de gerundio frente a un $50 \%$ que relacionó el sujeto del gerundio con un "Sujeto no especificado".

(5) a. Atrapé a mi perro Tobías, ( ) escapando a la media hora.

b. Te golpee a ti en el brazo, ( ) reclamándome luego por ello.

c Me regalaste un chocolate a mí, ( ) comiéndolo después de un rato.

d. Te ofrecieron una toalla a ti, ( ) ensuciándola más tarde.

Esto podría interpretarse como una asimetría en la vinculación del sujeto del gerundio con respecto a los complementos del verbo: hay una mayor identificación con el objeto directo que con el indirecto. No obstante, este nivel de procesamiento en la identificación de objetos va mucho más allá que la computación sintáctica; es decir, la identificación de individuo que realiza el hablante no está sujeta a una dependencia sintáctica, pues se trata de adjuntos oracionales, por tanto, de una operación inferencial entre dos predicados verbales. De esta manera, la identificación que realizan los hablantes es un proceso más complejo y abstracto, y un nivel mayor que la complementación sintáctica.

Otro aspecto importante es la interpretación laxa del sujeto del gerundio. Ello lo observamos con verbos como provocar, producir, generar, resultar, causar, originar, etc., con los que el gerundio puede tener como Sujeto al Sujeto del verbo finito o puede tomar como referencia la proposición descrita por la oración de tiempo finito: 
(6) El mandatario evitó dar declaraciones a la prensa, ( ) generando un fastidio general.

Donde el 50\% relacionó la proposición como Sujeto del gerundio frente a 33\% que identificó el Sujeto del gerundio con el Sujeto de verbo finito; y 16,7\% identificó "la prensa" como sujeto del gerundio.

(7) Las intensas lluvias no cesaron en los últimos días, ( )provocando deslizamientos cerca a los caseríos.

Donde el 66,7\% determinó la proposición como sujeto del gerundio frente a 33,3\% que reconoció el Sujeto del gerundio con el Sujeto de verbo finito.

(8) El auto se descompuso en plena avenida, ( ) originando una gran congestión en hora punta.

Donde el 50\% identificó la proposición como sujeto del gerundio frente a 33\% que identificó el Sujeto del gerundio con el Sujeto de verbo finito; 16,7\% identificó como Sujeto “Algo no especificado" en la oración.

La interpretación del sujeto del gerundio puede ser tanto el sujeto como la proposición del verbo finito. Sin embargo, aunque esta última interpretación de sujeto sea más laxa que la anterior, la vinculación semántica de los eventos sigue siendo estrecha.

\subsection{Interpretación de la posterioridad a partir del tiempo verbal del verbo finito} A continuación, presentaremos formas aceptables e inaceptables de la construcción del gerundio de posterioridad con respecto al tiempo descrito por la forma finita del verbo. Para medir la aceptabilidad de las oraciones, se ha tomado en cuenta el tiempo que describen los eventos del verbo principal ( $\mathrm{t}$ ), del gerundio ( $\left.\mathrm{t}^{\prime}\right)$ y el momento de enunciación del hablante (h). Una primera observación es que la información de tiempo gramatical es altamente restringido: el evento denotado por el verbo finito debe haber culminado cuando inicia el evento expresado por el gerundio. Veamos los resultados obtenidos:

(9) a. Juan caminó por la acequia, cayéndose después de unos minutos.

Donde el 66,7\% valoró la oración como “extraña pero aceptable”; el 16,7\%, como "aceptable"; y 16,7\% como "inaceptable". 
b. Juan ha caminado por la acequia, cayéndose después de unos minutos.

Donde el 66,7\% valoró la oración como "inaceptable"; el 16,7\%, como "aceptable"; y otro 16,7\% como "extraña pero aceptable".

c. Juan caminaba por la acequia, cayéndose después de unos minutos.

Donde el 66,7\% valoró la oración como "aceptable" y el 33,7\% como "extraña pero aceptable".

d. Juan caminará por la acequia, cayéndose después de unos minutos.

Donde el 88,3\% valoró la oración como "inaceptable"; y el 16,7\% como “extraña pero aceptable".

e. Juan camina por la acequia, cayéndose después de unos minutos.

Donde el 66,7\% valoró la oración como "inaceptable"; el 16,7\%, como "extraña pero aceptable"; y otro 16,7\%, como "aceptable".

Los juicios sobre las oraciones permiten vislumbrar la relación entre información de tiempo y el aspecto de la construcción. En(9a) el evento de 'caminar' culmina cuando ocurre el evento de 'caer', por tanto, el evento de 'caminar' ya concluyó en el momento de la enunciación de la oración: $(\mathrm{t}<\mathrm{h})$; en cambio en (9b), a diferencia del pretérito simple, el evento de 'caminar' sucede en un tiempo pretérito que se solapa con el tiempo de enunciación $(t=h)$, lo cual entraña que la acción de 'caminar' sigue presente en el momento de enunciar la oración, lo cual la hace anómala; (9c) describe que el evento de 'caminar' se desarrolla en un tiempo indeterminado, pero el gerundio fuerza una culminación de dicho evento; (9d) y (9e) son oraciones en tiempo futuro y presente respectivamente, donde la presencia de las frases adverbiales son inaceptables, pues el evento de 'caminar' aún no se realiza o se está llevando a cabo en el momento de la enunciación. Sin embargo, son aceptables si las frases adverbiales son eliminadas y los gerundios son construidos sin pausas con el verbo finito, lo que daría como resultado un gerundio de complemento y no de adjunto.

Por tanto, podemos concluir que el gerundio de posterioridad exige que el evento del verbo finito finalice para que se lleve a cabo el posterior, y no de forma simultánea. 
5.3 Interpretación del gerundio a partir de su posición con respecto al verbo finito

La posición del gerundio también es bastante restringida. Esta debe ser inmediatamente después del verbo finito y de sus complementos si los hubiese.

(10) a. Mariana trajo un platillo de camarones para nosotros, tirándolo a la basura luego por estar descompuesto.

Donde el 50\% valoró la oración como "aceptable; y el otro 50\% valoró como "extraña pero aceptable".

b. Tirándolo a la basura luego por estar descompuesto, Mariana trajo un platillo de camarones para nosotros.

Donde el 50\% valoró la oración como "inaceptable"; el 16,7 \%, como "aceptable; y otro 16,7\%, como "extraña pero aceptable".

$\mathrm{Si}$ alteramos el orden de los constituyentes, como en (10b), la interpretación también se altera. En esta última versión de la oración, el hablante interpreta que el evento descrito por el gerundio es la causa del evento que escribe el verbo finito: el hecho de que un comestible cuya existencia es supuesta en la oración haya sido desechado ocasionó que Mariana trajera otro plato. Por ello, el gerundio siempre va pospuesto al verbo finito.

\subsection{Interpretación del gerundio sin frases adverbiales de tiempo}

Como se ha observado, la presencia de frases adverbiales que denotan posterioridad es una pieza importante para la interpretación de dichos gerundios. La ausencia de estas frases oscurece la interpretación y dirige a una interpretación imprecisa. Para ello, se hizo el contraste entre la oración (11a) con frase adverbial y (11b) sin ella:

(11) a. Los cocineros estimaron conveniente preparar un menú costero, rechazándolo más tarde por no contar con los ingredientes suficientes.

Donde el 83,3\% valoró la oración como "aceptable; y el 16,7\%, como “extraña pero aceptable". 
b. Los cocineros estimaron conveniente preparar un menú costero, rechazándolo por no contar con los ingredientes suficientes.

Donde el 50\% valoró la oración como "inaceptable"; el 16,7\%, como "aceptable"; y el 33,3\%, como "extraña pero aceptable".

En la oración (11b), no es posible darle una interpretación de posterioridad, sino una de simultaneidad.

\subsection{Interpretación del gerundio con respecto al aspecto léxico del verbo finito}

Como una posible restricción a la producción de gerundios de posterioridad, hemos asumido que el aspecto léxico, definido como la constitución temporal denotada por el verbo (Morimoto, 1998), podría descartar el uso del gerundio de posterioridad en ciertos casos. Así, si el verbo finito no tiene un límite temporal en su estructura interna, como los verbos de estado (saber, tener, pertenecer, ser inteligente, etc.), cualquier construcción con dichos verbos y los gerundios de posterioridad devendrían en inaceptables; a diferencia de los verbos de actividad (correr, trabajar, dormir, jugar, etc.); de efectuación (matar, romper, correr cien metros, pintar un cuadro, etc.) y de logro (descubrir, alcanzar, llegar, cruzar una línea, etc.) que sí tienen una culminación. No obstante, luego de la aplicación de la encuesta, se obtuvo los siguientes resultados:

(12) a Ernesto presentó su escrito, siendo publicado meses después.

Donde el 66,7\% valoró la oración como "aceptable; el 16,7\%, como "extraña pero aceptable"; y el otro 16,7, como "inaceptable".

b. Adela llegó a su casa, echándose a su cama a la media hora.

Donde el 50\% valoró como "aceptable; y el otro 50\%, como "extraña pero aceptable".

c. Rubén corrió los 200 metros, ganando una medalla de bronce.

Donde el 66,7\% valoró como "aceptable; el 16,7\%, como "extraña pero aceptable"; y el otro 16,7\%, como "inaceptable".

d. Matías fue un buen pupilo, terminando de estudiar años después. 
Donde el 50\% valoró como oración "aceptable"; el 16,7\%, como "extraña pero aceptable"; y el 33,3\%, como "inaceptable".

e. Pedro tuvo un auto usado hace un año, malográndose luego de usarlo solo dos veces.

Donde el $66,7 \%$ valoró como "aceptable; y el 33,3\%, como "extraña pero aceptable".

En las formas (12) vemos una restricción débil o nula del aspecto léxico sobre los gerundios. Mientras se esperaba que las formas ( $12 \mathrm{~d}$ y e) fueran rechazadas, estas tuvieron un alto grado de aceptabilidad, al igual que los usos esperables (12a, b y c). Una explicación a ello es que el hablante reinterpretó el aspecto léxico de acuerdo con el aspecto gramatical, el cual fue el tiempo pretérito, ya que este es el uso habitual de los verbos finitos en construcciones con gerundios de posteridad. Por tanto, los verbos de estado, que no tienen estructura eventiva interna, fueron interpretados como culminados y, en consecuencia, como "aceptables".

5.6. Resumen

a. El gerundio de posterioridad ocurre luego de verbos finitos en pretérito simple o perfecto.

b. El gerundio de posterioridad comparte un individuo participante del verbo finito.

c. El gerundio es acompañado por adverbios temporales "luego", "después" o frases adverbiales de resultado "como resultado", etc.

d. El evento descrito por el gerundio sucede una vez culminado el evento del verbo finito.

\section{Discusión}

De acuerdo con nuestro análisis, hemos mostrado, en oposición a París (2003), que un gerundio adjunto requiere vinculaciones semánticas de (a) individuo y de (b) circunstancia, y no solamente una relación vaga de consecuencia o motivo. Con respecto a restricciones más específicas del gerundio de posterioridad, 
hemos comprobado que ciertos contextos lingüísticos son determinantes para obtener dicha interpretación. De mayor a menor grado, presentamos los condicionamientos:

a. Ubicación inmediata del gerundio con respecto al verbo finito.

b. Presencia de frase adverbial con denotación de posterioridad.

c. Vínculo con un individuo participante del verbo finito.

d. El aspecto gramatical del verbo finito.

e. El aspecto léxico del verbo finito.

No obstante, aún quedan por aclarar de qué manera las proposiciones pueden ser sujetos del gerundio. Este tipo de vinculaciones semánticas podrían darse en niveles más complejos que aquellos en los que se identifican con constituyentes menores (FD). Asimismo, se necesita un examen más exhaustivo sobre la interpretación del tiempo y el aspecto léxico de los verbos.

Por último, un estudio sobre las innovaciones gramaticales del gerundio y, en general, de otros aspectos de la sintaxis, debería dar cuenta de los correlatos con algún grupo sociolectal particular; por ello, sería recomendable un estudio sociolingüístico a mayor escala que considere variables sociales más específicas.

\section{Conclusiones}

La gramaticalidad del gerundio de posterioridad se fundamenta en aspectos de vinculación semántica con los individuos y aspectuales del verbo de la oración principal. Asimismo, la información temporal o modificación adverbial entre los eventos es determinante para su conformación.

Si bien el gerundio de posterioridad pertenece a la clase de adjuntos, equivalentes a una oración independiente, la construcción bajo estudio muestra características similares a los gerundios de complemento, en el sentido de que comparten individuos participantes del verbo finito, así como circunstancias del evento del verbo finito, vistos así los condicionamientos temporales y aspectuales impuestos. 
Revisados los condicionamientos que configuran las construcciones de gerundio de posterioridad, se vislumbra una gramática interna que permite al hablante producir e interpretar dichas formas. Evitarlas o censurarlas por criterios estilísticos o de prestigio no tiene ningún asidero científico, y peor aún, crea ideologías en contra de la gramática del hablante.

\section{Referencias bibliográficas}

Badía Magarit, A. M. (1964). El gerundio de posterioridad. En Oficina Internacional de Información y Observación del Español, Presente y futuro de la lengua española. Actas de la Asamblea de Filología del I Congreso de Instituciones hispánicas, vol. II (pp. 287-295). Madrid: Ediciones de Cultura Hispánica.

Bello, A. (1972 [1847]). Gramática. Caracas: Ministerio de Educación.

Bobes Naves, M. C. (1975). Sistema, norma y uso del gerundio castellano. Revista Española de Lingüística, 5 (1), 1-34.

Bouzet, J. (1953). Le gérondif espagnol dit “de posteriorité”. Bouletin Hispanique, 55, 343-374. https://doi.org/10.3406/hispa.1953.3367

Chomsky, N. (1986). Barriers. Massachusetts: MIT Press.

Cuervo, R. (1954). Apuntaciones críticas sobre el lenguaje bogotano. Bogotá: Voluntad.

De los Mozos, S. (1974). ¿Es arabismo sintáctico el gerundio de posterioridad? Revista Española de Lingüística, 4 (2), 375-389.

Fernández Lagunilla, M. (1999). Las construcciones de gerundio. En I. Bosque y V. Demonte (Eds.), Gramática descriptiva de la lengua española. Las construcciones sintácticas fundamentales. Relaciones temporales, aspectuales y modales. 2. ${ }^{a}$ edición (pp. 3443-3503). Madrid: Espasa.

Gili y Gaya, S. (1964). Curso superior de sintaxis española. Barcelona: Spes, S. A.

Morimoto, Y. (1998). El aspecto léxico: delimitación. Madrid: Arco Libros.

París, L. A. (2003). Grammatical Encoding of Event Relations. Gerund Phrases in Spanish (Disertación doctoral). Universidad de Búfalo, EE. UU.

Real Academia Española (2011). El verbo (V). Las formas no personales: el gerundio y el participio. En Nueva gramática de la lengua española (pp. 2037-2066) Madrid: Espasa. 


\section{ANEXO \\ Encuesta anónima}

Esta encuesta no es un examen de conocimientos, sino un instrumento de observación sobre juicios de hablante de castellano. Procure responder atendiendo a su intuición de cómo se enunciaría una oración comúnmente.

I. Lea con atención las oraciones que se le presentan y responda a la pregunta que le sigue:

(1) "El alumno desarrolló el examen, saliendo dos horas después".

¿Quién o qué salió?
a. El alumno
b. El examen
c. Alguien no especificado

(2) "Atrapé a mi perro Tobías, escapando a la media hora". ¿Quién escapó?
a. Yo
b. Mi perro Tobías 71
c. Alguien no especificado

(3) "Te golpee a ti en el brazo, reclamándome luego por ello". ¿Quién reclamó?
a. Tú
b. Yo
c. Alguien no especificado

(4) "Me regalaste un chocolate a mí, comiéndolo después de un rato". ¿Quién lo comió?
a. Yo.
b. Tú
c. Alguien no especificado

(5) "Te ofrecieron una toalla a ti, ensuciándola más tarde". ¿Quién la ensució?

(6) "El mandatario evitó dar declaraciones a la prensa, generando un fastidio general".

¿Qué o quién generó un fastidio?
a. El mandatario
b. la prensa
c. que el mandatario evitara dar declaraciones a la prensa

(7) "Las intensas lluvias no cesaron en los últimos días, provocando deslizamientos cerca a los caseríos".

¿Qué o quién provocó deslizamientos?
a. Las intensas lluvias
b. que las intensas lluvias
c. algo no especificado no cesaran 
(8) "El auto se descompuso en plena avenida, originando una gran congestión en hora punta".

¿Qué o quién originó una gran congestión?
a. Que el auto se descompusiera
b. El auto
c. algo no especificado en plena avenida

II. De acuerdo con su criterio, indique el grado de aceptabilidad de las siguientes oraciones:

(1) "Los alumnos desarrollaron el examen, saliendo el profesor dos horas después".
a. Aceptable
b. Extraña pero aceptable
c. Inaceptable

(2) "Los alumnos desarrollaron el examen, saliendo un profesor dos horas después".
a. Aceptable
b. Extraña pero aceptable
c. Inaceptable

(3) "Juan caminó por la acequia, cayéndose después de unos minutos".
a. Aceptable
b. Extraña pero aceptable
c. Inaceptable

(4) "Juan ha caminado por la acequia, cayéndose después de unos minutos".
a. Aceptable
b. Extraña pero aceptable
c. Inaceptable

(5) "Juan caminaba por la acequia, cayéndose después de unos minutos".
a. Aceptable
b. Extraña pero aceptable
c. Inaceptable

(6) "Juan caminará por la acequia, cayéndose después de unos minutos".
a. Aceptable
b. Extraña pero aceptable
c. Inaceptable

(7) "Juan camina por la acequia, cayéndose después de unos minutos".
a. Aceptable
b. Extraña pero aceptable
c. Inaceptable

(8) "Mariana trajo un platillo de camarones para nosotros, tirándolo a la basura luego por estar descompuesto".
a. Aceptable
b. Extraña pero aceptable
c. Inaceptable

(9) Tirándolo a la basura luego por estar descompuesto, Mariana trajo un platillo de camarones para nosotros.
a. Aceptable
b. Extraña pero aceptable
c. Inaceptable 
(10) Los cocineros estimaron conveniente preparar un menú costeño, rechazándolo más tarde por no contar con los ingredientes suficientes.
a. Aceptable
b. Extraña pero aceptable
c. Inaceptable

(11) Los cocineros estimaron conveniente preparar un menú costeño, rechazándolo por no contar con los ingredientes suficientes.
a. Aceptable
b. Extraña pero aceptable
c. Inaceptable

(12) Ernesto presentó su escrito, siendo publicado meses después.
a. Aceptable
b. Extraña pero aceptable
c. Inaceptable

(13) Adela llegó a su casa, echándose a su cama a la media hora.
a. Aceptable
b. Extraña pero aceptable
c. Inaceptable

(14). Rubén corrió los 200 metros, ganando una medalla de bronce.
a. Aceptable
b. Extraña pero aceptable
c. Inaceptable

(15). Matías fue un buen pupilo, terminando de estudiar años después.
a. Aceptable
b. Extraña pero aceptable
c. Inaceptable

(16) Pedro tuvo un auto usado hace un año, malográndose luego de usarlo solo dos veces.
a. Aceptable
b. Extraña pero aceptable
c. Inaceptable 